\title{
The Relation between Isokinetic Strength, Shoulder Mobility and Ball Velocity at Elite Male Volleyball Players
}

\author{
Yasin Arslan*, Faruk Albay \\ School of Physical Education and Sport, Gaziosmanpaşa University, Turkey
}

Copyright $\mathrm{C} 2019$ by authors, all rights reserved. Authors agree that this article remains permanently open access under the terms of the Creative Commons Attribution License 4.0 International License

\begin{abstract}
The working group of the current study which aims at investigating the relation of isokinetic strength, shoulder mobility and ball velocity at elite male volleyball players was made up of 20 male volleyball team players having the age, body weight and height means; $28,40 \pm 3,32$ age, $83,25 \pm 7,80 \mathrm{~kg}, 192,54 \pm 4,20 \mathrm{~cm}$ and volunteering in the study. The data obtained in the study was analysed in the package program of SPSS (Statistical Package for Social Sciences) for Windows 22.0. For all variables in the study, Pearson correlation test was applied. In the research, $60 \% \mathrm{sec}$. dominant and non-dominant, internal and external isokinetic strength values (nm) were found as $70,07 \pm 6,20$, $66,57 \pm 6,12, \quad 40,57 \pm 7,90, \quad 39,23 \pm 8,49, \quad$ respectively. Dominant internal rotation values of the players were found as $60,18^{\circ} \pm 7,58$, dominant external rotation values were found as $105,00^{\circ} \pm 8,47$, non-dominant internal rotation values were found as $56,00^{\circ} \pm 4,07$, non-dominant external rotation values were found as $100,71^{\circ} \pm 8,70$. Service speed $(\mathrm{km} / \mathrm{h})$ was $70,55 \pm 3,66$. As a conclusion, upon the investigation of the correlation values between isokinetic strength, shoulder joint mobility and ball velocity at elite male volleyball players, a statistically direct relation was not found between them at the level of $\alpha=0.05$ significance.
\end{abstract}

Keywords Volleyball, Isokinetic Strength, Shoulder Mobility, Ball Velocity

\section{Introduction}

Today, volleyball is a sport branch which is in a continual development and comprising complex movements. A total 250-300 movements that requires high level strength are applied in a match with five sets [1]. For that reason, strength which is one of the most significant components of a sport in order both to prevent injuries and for a high performance has been a very important motoric feature for volleyball. Shoulder joint is the most active joint of the body. The mechanism of shoulder joint allows us to align the position of hand in front of the body. In this sense, it controls the elbow joint and helps us with fulfilling the motor functions [2].

In order to determine the performance that is put forth during dynamic muscle construction, it is necessary to measure the strength and power produced at a certain angular speed. These values are given numerically by means of isokinetic dynamometer [3]. Determining the isokinetic strength profiles of the sportspersons in different branches is of great importance in terms of fulfilling the requirements of the branch and the continuity of the high level performances of the sportspersons. Volleyball is one of these branches [4].

One of the basic techniques in volleyball is certainly serve. Serve in volleyball could be considered as the first attack movement of each rally. Serve speed is one of the important elements determining the serve quality [5]. Evaluating the performance put forth in the ball games is much harder compared to individual sports. The match in such kind of games is determined depending on the points, sets won and the goals scored [6].

The introduction of science into sport with the development of technology today and the fact that sport starts to benefit from the scientific data has increased competition and it has become a process where split seconds compete instead of seconds. It is likely to see studies in the literature regarding the fact that biomechanical and physiological factors affect the success of sportspersons directly [7]. For that reason, evaluating dynamic performance in sport sciences and determining the results quantitatively has become one of the most important issues. Also, as for the international studies in the literature, while there are some researches investigating the changes on the shoulders of the athletes dealing with the sports where overhead techniques are applied and the relation between the strength and angles, such kind of studies are limited in national publications. 
When considered that a volleyball player spikes about 40.000 times in a competition season [9], it is clearly understood how shoulder strength and mobility are important in volleyball.

Depending on this limitation, the purpose of the current study is to determine the relation between the ball velocity and shoulder mobility which has a direct effect on the volleyball game and shoulder strength, making a contribution to the literature and training program.

\section{Method}

\subsection{Study Group}

The study group of the study was made up of 20 male volleyball team players having the mean age of $28,40 \pm 3,32$, mean body weight of $83,25 \pm 7,80 \mathrm{~kg}$ and mean height of, $192,54 \pm 4,20 \mathrm{~cm}$ and volunteering in the study.

\subsection{Data Collection}

\subsubsection{Isokinetic Strength Measures}

Isokinetic strength measures of the subjects were carried out by sport medicine physicians with isomed 2000 isokinetic dynamometer. Before the evaluations of strength, each participant was taken into a standard warm-up program individually as much as possible (10-15 min). The participants were made to warm-up with arm ergometer and stretching exercise in the warm-up program. After special warm-up, the subjects were taken at the isomed device one by one to make measurements and the machine set-up was made according to individual anthropometric features. The body of the subject to be measured was immobilized in a way not to affect the test and after that, personal data was entered on the computer and the preparations for the test were completed. The dynamometer axis was aligned according to shoulder rotation axis at the dominant side.

\subsubsection{Internal - External Rotation Measurements}

Internal and external rotation measurements were recorded actively by specialist physiotherapists with universal goniometer. The measurements were made when the subjects were at the supine position with the shoulder at 90-degree abduction and with the elbow at flexion position.

\subsubsection{Ball Velocity Measurements}

The measurements were made with the speed measuring device of the brand mark of Ball Coach Radar ${ }^{\mathrm{TM}}$ (Model PR1000-BC-USA). The speed device is a device with sensitivity of $\pm \mathrm{mph} / \mathrm{sa}$ which has a radar ability being able to measure at $25 / 130 \mathrm{mph} / \mathrm{sa}$. The sportspersons were asked to serve the ball in the court with their maximum strengths and they were informed that the out balls would also be measured with an idea of eliminating the concern that they would throw the ball out. The measurements were recorded at a distance of $18 \mathrm{~m}$ of the other side of the net, against the ball. The sportspersons were also asked to serve not towards the target but in a way to pass the ball over the net with their full strengths and each sportsperson was asked to repeat it three times and the best score was recorded.

\subsubsection{Statistical Analysis}

The data obtained in the research was analysed using the SPSS (Statistical Package for Social Sciences) for Windows 22.0 program. In the evaluation of the data, maximum value, minimum value, arithmetic mean and standard deviation were used as the descriptive statistics. Normality test was made for all variables in the research. All the variables comply with the normal distribution at alpha $=0.05$ significance level. For that reason, Pearson correlation test, a parametric test, was applied for all the variables in the research

\section{Findings}

The demographic information regarding the male volleyball players in the research, the values of the isokinetic strengths, measurements of shoulder joint mobility, ball velocity measurements and their relations with each other were given in tables below.

Table 1. Information regarding the study group

\begin{tabular}{cccc}
\hline Variables & $\mathrm{n}$ & $\overline{\boldsymbol{x}}$ & $\mathrm{SD}$ \\
\hline Age (year) & 20 & 28,4 & 3,3 \\
\hline Body Weight $(\mathrm{kg})$ & 20 & 83,23 & 7,8 \\
\hline Body Height $(\mathrm{cm})$ & 20 & 192,54 & 4,2 \\
\hline
\end{tabular}

Table 2. $60 \% \mathrm{sec}$. Internal and external isokinetic strength values

\begin{tabular}{lcccccc}
\hline \multicolumn{2}{l}{ Isokinetic Strength } & $\mathrm{n}$ & Maximum & Minimum & $\bar{x}$ & $\mathrm{SD}$ \\
\hline D. IS & $(\mathrm{Nm})$ & 20 & 77,3 & 46 & 52,07 & 6,2 \\
\hline D. ES & $(\mathrm{Nm})$ & 20 & 55,2 & 32,1 & 40,57 & 7,9 \\
\hline N.D. IS & $(\mathrm{Nm})$ & 20 & 72,8 & 33,1 & 48,57 & 6,1 \\
\hline N.D. ES & $(\mathrm{Nm})$ & 20 & 47,1 & 16,5 & 39,23 & 8,4 \\
\hline
\end{tabular}

D. IS: Dominant Internal Strength

D. ES: Dominant External Strength

N.D. IS: Non-Dominant Internal Strength

N.D.ES: Non-Dominant External Strength

Table 3. Shoulder rotation measurement values

\begin{tabular}{cccccc}
\hline $\begin{array}{c}\text { Shoulder } \\
\text { Rotation }\end{array}$ & $\mathrm{n}$ & Maximum & Minimum & $\bar{x}$ & SD \\
\hline D. IR & 20 & 70 & 47 & 57,18 & 7,58 \\
\hline D. ER & 20 & 124 & 86 & 105 & 8,42 \\
\hline N.D. IR & 20 & 62 & 73 & 56 & 4,07 \\
\hline N.D. ER & 20 & 117 & 87 & 100,71 & 8,7 \\
\hline
\end{tabular}

D. IR: Dominant Internal Rotation

D. ER: Dominant External Rotation

N.D. IR: Non-Dominant İnternal Rotation

N.D. ER: Non-Dominant External Rotation 
Table 4. Serving velocity values

\begin{tabular}{cccccc}
\hline Serving Velocity & $\mathrm{n}$ & Maximum & Minimum & $\bar{x}$ & $\mathrm{SD}$ \\
\hline $\begin{array}{c}\text { Dominant SV } \\
(\mathrm{mph} / \mathrm{h})\end{array}$ & 20 & 88 & 50 & 70,55 & 3,66 \\
\hline
\end{tabular}

SV: Serving Velocity

Table 5. Correlation values between the external rotation and internal rotation strength values

\begin{tabular}{cccc}
\hline Variables & $\mathrm{n}$ & $\mathrm{r}$ & $\mathrm{p}$ \\
\hline D. ER-D. IS & 20 & 0,09 & 0,8 \\
\hline N.D ER-N.D IS & 20 & 0,136 & 0,69 \\
\hline
\end{tabular}

D. ER: Dominant External Rotation

D.IS: Dominant Internal Isokinetic Strength

N.D. ER: Non-Dominant External Rotation

N.D. IS: Non-Dominant Internal

Table 6. Correlation values between the internal rotation and external isokinetic strength values

\begin{tabular}{cccc}
\hline Variables & $\mathrm{n}$ & $\mathrm{r}$ & $\mathrm{p}$ \\
\hline D. IR- D. ES & 20 & 0,39 & 0,2 \\
\hline N.D IR- N.D ES & 20 & 0,245 & 0,26 \\
\hline
\end{tabular}

D. ES: Dominant External Isokinetic Strength

D. IR: Dominant Internal Rotation

N.D. IR: Non-Dominant İnternal Rotation

N.D. ES: Non-Dominant External Isokinetic Strength

Table 7. Correlation Values between Isokinetic Strength and Ball Velocity

\begin{tabular}{cccc}
\hline Variables & $\mathrm{n}$ & $\mathrm{r}$ & $\mathrm{p}$ \\
\hline D. IS $\left(60^{\circ} / \mathrm{sec}\right)-\mathrm{BV}$ & 20 & 0,39 & 0,226 \\
\hline D. ES $(60 \% \mathrm{sec})-\mathrm{BV}$ & 20 & $-0,044$ & 0,936 \\
\hline
\end{tabular}

D. IS: Dominant Internal Isokinetic Strength

BV: Ball velocity

D. ES: Dominant External Isokinetic Strength BV: Ball Velocity

Table 8. Correlation values between the internal-external rotation and ball velocity

\begin{tabular}{cccc}
\hline Variables & $\mathrm{n}$ & $\mathrm{r}$ & $\mathrm{p}$ \\
\hline D. IR-BV & 20 & 0,104 & 0,755 \\
\hline D. ES-BV & 20 & $-0,136$ & 0,697
\end{tabular}

D. IK: Dominant İnternal Isokinetic Strength

D. EK: Dominant External Isokinetic Strength

BV: Ball Velocity

\section{Discussion}

In sport sciences, achievement of sportspersons to the optimum performance level and maintenance of that level is only possible with the well-planned training programs based on scientific data [8]. When considered that a volleyball player spikes about 40.000 times in a competition season [9], it is clearly understood how shoulder strength and mobility are important in volleyball. Today, the variables directly affecting success and the perfectness of which skills has an impact on winning are the issues upon which trainers think the most.

It was found that the mean age of the elite male volleyball players was $28.40 \pm 3.32$ age, body weight was $83.25 \pm 7.80 \mathrm{~kg}$ and height was $192.54 \pm 4.20 \mathrm{~cm}$ in the current study which investigates the relation between the ball velocity and shoulder mobility and the shoulder strength which has a direct effect on the game in volleyball.

It was also found that $60 \% \mathrm{sec}$ dominant and nondominant internal and external isokinetic strength values of the volleyball players were $(\mathrm{Nm}) ; 52,07 \pm 6,20,48,57 \pm 6,12$, $40,57 \pm 7,90,39,23 \pm 8,49$, respectively. Related literature has parallel outcomes with the ones found in the current study. Alfredson et al. [10], found in their studies carried out over Swedish female volleyball players that dominant external isokinetic strength values were $28,7 \pm 6,7 \mathrm{Nm}$, non-dominant external isokinetic strength values were $29,5 \pm 7,3 \mathrm{Nm}$, dominant internal isokinetic strength values were $40,1 \pm 7 \mathrm{Nm}$, and non-dominant internal isokinetic strength values were $37,8 \pm 9,2 \mathrm{Nm}$.

With regard to the shoulder rotation values of the male volleyball players in the current study, it was found that dominant internal rotation value was $57,18^{\circ} \pm 7,58$, dominant external rotation value was $105,00^{\circ} \pm 8,42$, non-dominant internal rotation value was $56,00^{\circ} \pm 4,07$, and non-dominant external rotation value was $100,71^{\circ} \pm 8,70$. Upon the literature review, the significant abundancy of the external rotation angles frequently encountered in the branches having overhead hit compared to internal rotation angles is striking in this data. In a study carried out by Herrington [11] over javelin throwers, it was found that external rotation range of motion at dominant shoulder was higher compared to internal rotation range of motion. Carcia et al [12] pointed out that this increase at the external rotation range of motion develops depending on the repeated overhead activities.

Regarding the serving speed of the male volleyball players in the current study, it was $70,55 \pm 3,66 \mathrm{~km} / \mathrm{h}$. Häyrinen et al. [13] found in their studies carried out over male national volleyball players of Finland that the serving speed of the players was $70.92 \mathrm{~km} / \mathrm{h}$. In another study by Cerrato et al. [14] carried out over female volleyball players, the serving speed of the sportspersons was found as $45,08 \pm 6,30 \mathrm{~km} / \mathrm{h}$.

As for the relation between the shoulder rotations of the elite volleyball players and isokinetic strength values, it was found that dominant external rotation/dominant internal strength $\left(60^{\circ}\right)$ correlation values $(r)$ were 0.090 and non-dominant external rotation/non-dominant internal strength $\left(60^{\circ}\right)$ was 0.136 . There was no direct relation between the variables at the significance level of $\alpha=0.05$.

When it comes to the correlation values between dominant and non-dominant isokinetic strength and shoulder rotation (r), no direct relation was found between internal rotation/dominant external strength $\left(60^{\circ}\right), 0.390$, non-dominant internal rotation/non-dominant external strength $\left(60^{\circ}\right) 0.245$ at the significance level of $\alpha=0.05$. Depending on the findings obtained, it was found that a 
sportsperson with high shoulder rotation values, in other words a players having a more flexible shoulder joint, was not able to produce more shoulder mobility.

While the correlation values between internal isokinetic strength of the male volleyball players and ball velocity (r); dominant internal isokinetic strength $\left(60^{\circ} / \mathrm{sn}\right)$ ball velocity was found 0.390 and external isokinetic strength $\left(60^{\circ} / \mathrm{sn}\right)$ was found as -0.044 , once again, a direct relation was not found between the variables at the significance level of $\alpha=0.05$.

The correlation values between internal-external rotation of the elite volleyball players and ball velocity (r) was found $0.104,-0.136$, respectively, a direct relation was not found between these variables at the significance level of $\alpha=0.05$. That is to say, depending on the results obtained from the correlation values, it was found that a sportsperson with a high strength value was not able to serve faster. It is likely to see in the related literature that there is no statistical significance between the isokinetic strength, shoulder joint mobility and ball velocity. In a study carried out by Fleck et al. [15] over handball players, no statistically significance difference was found between the isokinetic strength, shoulder joint mobility and ball velocity. While it is thought that the serving speed of a sportsperson with high internal rotation strength will also increase at the same level, no statistically direct correlation was not found between them.

This case could be related to other factors in serving. Depending on the findings obtained in the study, it is likely to say that not only a sportsperson with high strength value can serve. As seen in the literature, serving and ball velocity in volleyball could be affected by such factors as lacking technical components, concern, self-esteem, motivation and sport age [16]. On the other hand, aerodynamic principles could also affect the time in the air for the ball, the distance of flying and its speed. The holes on the golf ball, curvilinear lines on tennis, cricket and baseball balls and the stitches on the soccer ball are aerodynamic factors.

These all make balls attain various aerodynamic effects. These features affect the direction of the ball and its time in the air [17]. In this sense, it will not be wrong for the trainers to take other parameters into consideration instead of focusing only on the strength characteristics of the players. The negative correlation between the excess at shoulder mobility and strength have been pointed out in the studies carried out in this sense [18],[19]. Depending on the results obtained in the current study, it was found that a players having a high external and internal shoulder mobility, therefore having a flexible shoulder joint was not able to produce more internal isokinetic strength.

\section{Conclusions}

In the current study investigating the relation between isokinetic strength, shoulder joint mobility and ball velocity, depending on the results obtained based on the findings of the research, a direct relation was not found between the isokinetic strength, shoulder joint mobility and ball velocity at the significance level of $\alpha=0.05$.

Even though a very slight correlation was found between the parameters of shoulder mobility, isokinetic strength and ball velocity, it was not found significant in terms of the science of statistics.

\section{REFERENCES}

[1] Cinemre, A., Ünver, E. (2013). Voleybolda Kuvvet ve Güç Antrenmanları. 5. Antrenman Bilimi Kongresi, Ankara.

[2] Jobe, CM., Phipatanakul, WP., Coen, MJ. (2009). Gross Anatomy of the Shoulder in: the Shoulder. Editörler: Charles A, Frederick, AM., Rockwood, JR., Michael, AW., Steven, BL. Fourth Edition. Volume 1.Saunders Elsevier, S;213-233.

[3] Brochu, M., Savage, P., Lee, M., Dee, J., Cress, M. E., Poehlman, ET., Ades, PA. (2002). Effects of Resistance Training on Physical Function in Older Disabled Women with Coronary Heart Disease. Journal of Applied Physiology, 92(2), 672-678.

[4] Magalhaes, J., Olıveira, J., Ascensao, A., Soares, J. (2004). Concentric Quadriceps and Hamstrings Isokinetic Strength in Volleyball and Soccer Players. Journal of Sports Medicine Phys Fitness. 44(2):119-25.

[5] Deprá P, Brenzikofer R, Goes M, Barros R (1998). Fluid Mechanics Analysis in Volleyball Services. In H. J. Riehle \& M. M. Vieten (Eds.), 16. International Symposium on Biomechanics in Sports, Konstanz, Germany: ISBS. 85-88.

[6] Carling, C., Williams, AM., Reilly, T., (2005). Handbook of Soccer Match Analysis. New York: Routledge Taylor and Francis Group, 1.

[7] Reeser, JC. Bahr, R. (2003). Handbook Sports Medicine and Science Volleyball. 1-10. John Wiley \&Sons.

[8] Macdermid PW, Stannard S. (2012). Mechanical Work and Physiological Responses to Simulated Cross Country Mountain Bike Racing. J Sports Sci, 30(14): 1491-1501.

[9] Linfeng, Z. (1999). Application of SPA Degrees of Connection in Analysis of Smash Scoring in Powerful Women Volleyball Teams of the World [J]. JOURNAL OF BEIJING UNIVERSITY OF PHYSICAL EDVCATION,

[10] Alfredson, H., Pietilä, T., Lorentzon, R. (1998). Concentric and Eccentric Shoulder and Elbow Muscle Strength in Female Volleyball Players and Non-Active Females. Scandinavian Journal of Medicine \& Science In Sports, 8(5), 265-270.

[11] Herrington, L. (1998). Glenohumeral Joint: Internal and External Rotation Range of Motion in Javelin Throwers. British Journal of Sports Medicine, 32(3), 226-228.

[12] Carcia, CR., Cacolice, PA., Scibek, JS. (2013). Sidelying Glenohumeral Passive Internal Rotation Range of Motion Values in A Healthy Collegiate Population. The 
International of Sports Physical Therapy, December; $8(6) ; 793$

[13] Häyrinen, M., Lahtinen, P., Mikkola, T., Honkanen, P., Paananen, A., \& Blomqvist, M. (2007). Serve speed analysis in men's volleyball. Science for Success II, 10.

[14] Cerrato, D. V., Andrés, J. M. P., Marzo, P. F., Puche, P. R., \& Espá, A. U. (2007). Validity and reliability of radar to spike speed control in volleyball. Cultura_Ciencia_Deporte 2(6), 131-138.

[15] Akarcesme, C. (2004). Voleybolda Musabaka Oncesi Durumluk Kaygi Ile Performans Olcutleri Arasindaki Iliski. Gazi Universitesi, Saglik Bilimleri Enstitusu, Yüksek Lisans Tezi, Ankara.

[16] Beach, ML., Whitney, SL.,Dickoff-Hoffman, SA. (1992). Relationship of shoulder flexibility, strength, and endurance to shoulder pain in competitive swimmers. Journal of

[17] Fleck, SJ., Smith, SL., Craib, MW., Deneham, T., Snow, RE., Mitchell, ML., (1992). Upper Extremity Isokinetik Torque and Throwing Velocity in Team Handball. The Journal of Applied Sport Science Research, 6: 120-4.

[18] Mehta, RD., Pallis, JM. (2001). Sports Ball Aerodynamics: Effects of Velocity. Spin and Surface Roughness. Materials and Science in Sports; 185-197.

[19] Şahin, Ö. (2010). Rehabilitasyonda İzokinetik Değerlendirmeler. Cumhuriyet Medical Journal, 32(4), 386-396. 